\title{
Analysis of Plant Species in Elementary School Textbooks in South Korea
}

\author{
Min Hyeong Kwon \\ Senior researcher, Institute of Life Science and Natural Resources, Korea University, Seoul 02841, Korea
}

\section{ABSTRACT}

Background and objective: This study was conducted to find out the status of plant utilization in the current textbooks by analyzing the plants by grade and subject in the national textbooks for all elementary school grades in the 2015 revised curriculum in Korea.

Methods: The data collected was analyzed using Microsoft Office Excel to obtain the frequency and ratio of collected plant data and SPSS for Windows 26.0 to determine learning content areas by grade and the R program was used to visualize the learning content areas.

Results: A total of 232 species of plants were presented 1,047 times in the national textbooks. Based on an analysis of the plants presented by grade, the species that continued to increase in the lower grades tended to decrease in the fifth and sixth grades, the upper grades of elementary school. As for the number and frequency of plant species by subject, Korean Language had the highest number and frequency of plant species. The types of presentation of plants in textbooks were mainly text, followed by illustrations and photos of plants, which were largely used in first grade textbooks. In addition, as for the area of learning contents in which plants are used, in the lower grades, plants were used in the linguistic domain, and in the upper grades, in the botanical and environmental domains of the natural sciences. Herbaceous plants were presented more than woody plants, and according to an analysis of the plants based on the classification of crops, horticultural crops were presented the most, followed by food crops. Out of horticultural crops, flowering plants were found the most diversity with 63 species, but the plants that appeared most frequently were fruit trees that are commonly encountered in real life.

Conclusion: As a result of this study, various plant species were included in elementary school textbooks, but most of them were horticultural crops encountered in real life depending on their use. Nevertheless, plant species with high frequency have continued a similar trend of frequency from the previous curriculums. Therefore, in the next curriculum, plant learning materials should be reflected according to social changes and students' preference for plants.

Keywords: elementary school curriculum, environmental education, plant education, horticultural crops

\section{Introduction}

The elementary school curriculum in South Korea started with the first curriculum in 1954 after the founding of the country and has now reached the revised curriculum in 2015. The learning goal of the current curriculum, which has changed according to the trends and demands of the times, is to foster creative and interdisciplinary talented individuals and cultivate human personality based on such values, and for this purpose, a student-centered learning method through self-directed learning was suggested (MOE, 2015; NCIC, 2021).

Textbooks are the official basic learning materials used directly by children and occupy a large proportion and play a big role in the field of public education (Park, 2003). Several studies have reported that the content of textbooks related to daily life induced students' interest and attention and motivated them to learn about such content, bringing about self-directed learning effects (Ahn, 2012; Choi, 2007; Seo, 2009).

This research was supported by Basic Science Research Program through the National Research Foundation of Korea(NRF) funded by the Ministry of Education (no. 2019S1A5B5A07111953)

Received: July 29, 2021, Revised: August 26, 2021, Accepted: September 11, 2021

First author: Min Hyeong Kwon, jasminemin@korea.ac.kr, (1) https://orcid.org/0000-0003-3005-9743

*Corresponding author: Min Hyeong Kwon, jasminemin@korea.ac.kr, (1) https://orcid.org/0000-0003-3005-9743 
In addition, it was reported that eco-friendly learning linked to real life in the curriculum not only increased the will to practice the content in daily life, but also greatly enhanced various thinking skills, imagination, understanding, and desire to know more, and ultimately served as a driving force to awaken awareness about environmental conservation (Lee and Cho, 2005; Park and Cho, 2009).

Of the various subjects taught in elementary school, those related to plants can be considered very important with regard to environmental issues which are currently a cause for global concern. A related study found that plant names in textbooks motivated students to learn about those plants and allowed them to find and recognize plants on their own in their daily life (Yun and Rim, 2000); the important value of plants obtained through this inquiry process was extended to their awareness of natural environment conservation (Nam, 2006).

Recently there has been a growing interest in the plants included in textbooks according to domestic and international environmental trends and various analyses and research have been conducted on them. First of all, starting with the research on the classification of plant species presented in textbooks on the $5^{\text {th }}, 6^{\text {th }}, 7^{\text {th }}$ curriculum as well as the 2007 revised one (Chun, 2014; Kim, 2004; Lim, 2007; Park, 2003), research has been conducted that included frequency analysis of plant species appearing in the scientific and biological domain textbooks (Bae, 2009; Kim, 2008; Lim, 2003), and content analysis, recognition and preference of plants in textbooks (Bae, 2009; Kim, 2008; Lim, 2003; Kim, 1998; Pyo,
2001; Yun and Rim 2000). However, research on the status of plants and the classification of crops in the textbooks on the current curriculum revised in 2015 was not conducted.

Therefore, the purpose of this study is to lay the foundation for the improvement of the next curriculum by understanding the status of plant learning through an analysis of plants in the current national textbooks, which are common textbooks for public education in elementary schools, and the aspects of cultivated plants encountered in real life; and to present an educational vision for elementary school students in order to foster an eco-friendly human personality.

\section{Research Methods}

\section{Subjects}

This study investigated a total of 94 textbooks for the $1^{\text {st }}$ and $2^{\text {nd }}$ semesters of the $1^{\text {st }}$ to $6^{\text {th }}$ grades of elementary school, which were revised in 2015 and issued by the Ministry of Education, and the classification of textbooks was based on the system of the Ministry of Education (MOE, 2015). However, the subjects of spring, summer, fall, and winter in the first and second grades $\left(1^{\text {st }}\right.$ and $2^{\text {nd }}$ semesters $)$, which integrated subjects such as Moral Life, Pleasant Life, and Inquiring Life on the previous curriculum, were categorized and analyzed as an integrated subject cluster in this study (Table 1).

Table 1. Classification of elementary school textbook subjects by grade level

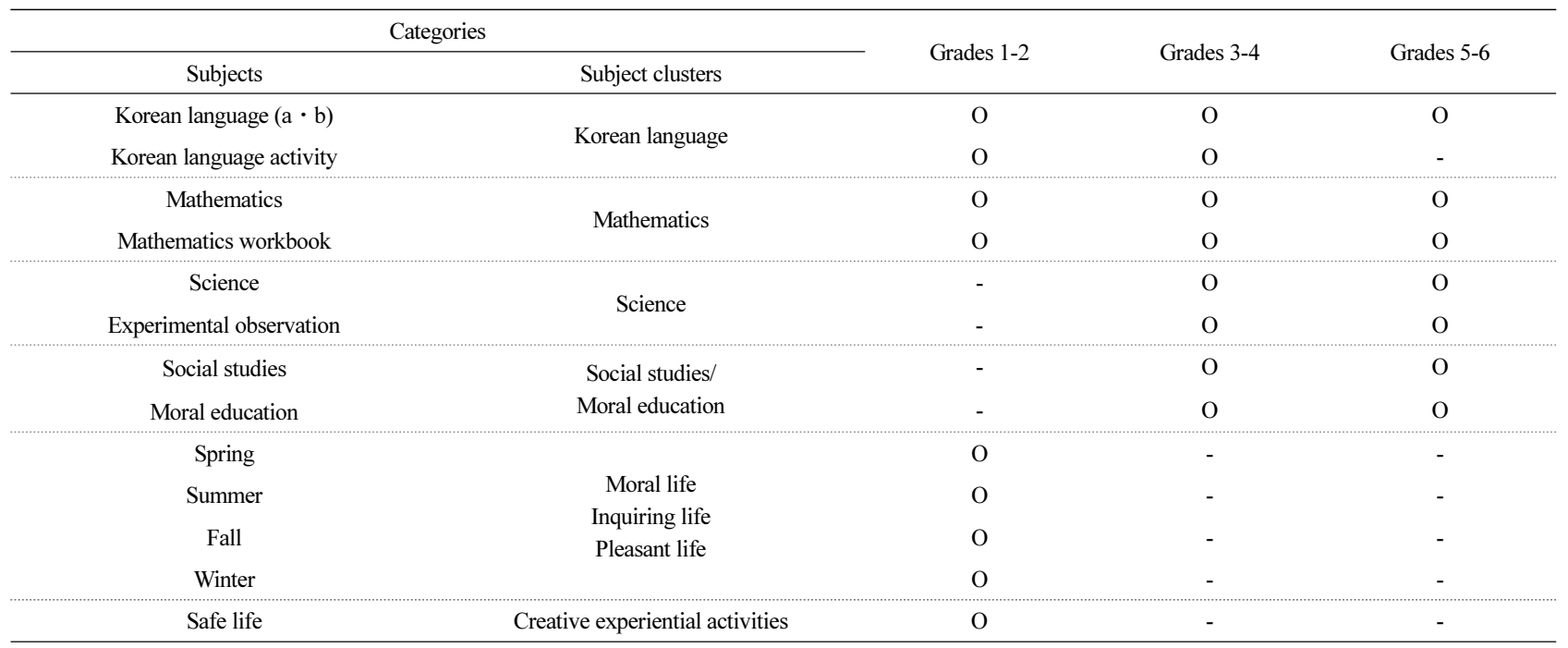




\section{Methods}

\section{Investigation method}

First, the species and frequency of plants in the textbooks were investigated and analyzed as follows based on vascular plants including bryophytes, pteridophytes, gymnosperms, and angiosperms, which are four taxa of plants. Plants were determined based on specific plant names or clearly recognizable illustrations or photographs, excluding pictures or patterns of plants presented in the background regardless of the textbook contents; non-regenerative forms such as plants whose original form was destroyed; and unclear metaphorical expressions. Parts that overlapped with learning units such as activity materials and stickers other than the textbook contents were also excluded. A plant name was chosen even if only a part of the plant was described, such as flowers and fruits, and for fruits, if only the name of a fruit was presented, it was considered as a botanical name and investigated (e.g. persimmon $\rightarrow$ Diospyros kaki). If different names for the same plant was presented, the name of the plant was applied preferentially based on the Korean Plant Names Index (KFS, 2021), and for parts that need further confirmation, the plant names were unified by additionally referring to the Standard Korean Dictionary of the National Institute of Korean Language (NIKL, 2021). On the list of investigated plants, the scientific names were presented as general information; The scientific names of plants were based on the Korean Plant Names Index (KFS, 2021), but if a scientific name was not listed in the Index, or needed to be reconfirmed, it was prepared by referring to the USDA GRIN (2021), a genetic resource information network of the United States Department of Agriculture.

For other parts not covered by those databases, Nongsaro, an agricultural technology portal (RDA, 2021), was referenced.

Second, for species and frequency of plants in textbooks by grade, all textbooks of each grade were investigated to find out which grade covered the most plants.

Third, for species and frequency of plants presented by subject, the number of plant species in each subject textbook was investigated to compare which subjects covered the most plants.

Fourth, to determine how plants were presented in textbooks, the types of presentations were classified into text, illustrations, and photos and then analyzed. Plants derived from the textbooks were counted once and summed up when they were presented repeatedly based on a unit; however, when they were presented simultaneously in the form of text, picture, and photograph, they were counted once for each presentation type. When two or more images of a single plant were presented in the same unit of the textbook, the upper-level plant part was selected (eg, an entire plant $>$ leaves of the plant).

Fifth, for classification based on areas of learning content using presented plants, the plant-related learning content items of Park (2003) and Park (2004) were referenced and they were reorganized and classified into 7 areas to fit this study: instrumental (calculation, examples and material of content, shape comparison); cultural (story material, song lyrics, poetry and letter content, and proverbs), symbolic (seasons: spring, summer, fall, winter, country and region including trade, city, province), botanical (physiology, characteristics, structure, classification and growth process of plants, habitats, and cultivation), linguistic (speech sound, text, listening, writing, speaking), artistic (drawing, art activity, musical instruments), and environmental (local environment, natural environment and protection, climate environment and ecosystem).

Sixth, the classification based on the characteristics of plants was largely divided into herbaceous and woody plants; and herbaceous plants were sub-divided into annual and biennial plants, and perennial plants, and woody plants were sub-divided into (tall) trees, shrubs, and vines according to the characteristics.

Finally, by applying the classification of crops, which is a classification system based on the use of cultivated plants, we tried to investigate the connection between the plants in the textbooks and real life. The classification of crops was divided into food crops, industrial crops, medicinal crops, stimulant crops, and horticultural crops (Park. et al., 2006), and other categories included forest trees (NIFS, 2021), wild flowers (RDA, 2013) and weeds (RDA, 2018). Among them, the sub-categories of horticultural crops were classified into vegetables, fruit trees, and flowering plants by referring to the studies of Lee (2008) and Moon et al. (2010). For each category, flowering plants were largely divided into herbaceous and woody plants (Lee 2008); vegetables were classified into leaf vegetables, immature flower bud, stem 
vegetables, root vegetables, fruit vegetables and sprout vegetables with reference to World Vegetables (Rubatzky and Yamaguchi, 2012); and fruit trees were classified into temperate, tropical and subtropical fruit trees with reference to Special Fruit Science (Lim, 2016) and New Subtropical and Tropical Fruit Trees (NIHHS, 2020). In addition, the citrus category was determined by referring to Citrus Varieties (Kim, 2008). Crops among plants were classified based on their high frequency of use to avoid overlaps between categories.

\section{Statistical analysis method}

For the collected plant data, frequency analysis was performed using the Microsoft Office Excel program (version 2019).

In addition, a chi-squared test was performed after crosstabulation analysis using the SPSS WIN 26.0 program to determine the differences in learning content areas in which plants were used according to grades, and a heat map was drawn by using the $\mathrm{R}$ program to visualize the learning content areas (Kwon, 2016).

\section{Results and Discussion}

\section{Species and frequencies of plants}

As a result of analyzing 94 national textbooks for all grades on the 2015 revised elementary school curriculum, the number of plants in the textbooks was 232 species, with a total frequency of 1,047 .

As shown in Table 2, of the plants in the textbook, Malus pumila had the highest frequency of appearance with a total of 75 times, followed by Glycine $\max$ (43 times) and Musa $\times$ paradisiaca (29 times). Eight species of plants appeared more than 20 times in textbooks, including Castanea crenata and Solanum lycopersicum (22 times each), and Citrullus vulgaris, Citrus unshiu and Fragaria $\times$ ananassa (21 times each), which were mainly edible plants. On the other hand, it was found that the frequency of flowering plants gradually increased among the plants with a lower frequency of less than 20 times. Also, of plants with a frequency of less than twice, 107 plants appeared once, which accounted for a relatively high proportion of all the plants. For Malus pumila, which had the highest frequency among them, both the previous 7th curriculum (Park, 2003) and the 2007 revised curriculum (Chun, 2014) showed the same results.

Compared with the above results, 17 species of plants, which were found more than 20 times based on research of plants in the national textbooks on the 2007 revised curriculum (Chun, 2014), decreased by 9 species on the current curriculum. Of the 17 species, flowering plants including Pinus densiflora, Hibiscus syriacus, Rosa spp., Forsythia koreana, and Taraxacum platycarpum were all reduced in frequency by more than half on the current curriculum, showing the frequency of appearance less than 15 times. Of the 17 species, it was found that 12 species except flowering plants were all mainly food plants, as in the current textbooks. On the other hand, the number of plants that appeared only once increased from 69 species to 107 species, a 1.5-fold increase in textbooks of the current curriculum (Table 2), indicating that this is a meaningful trend in that new plants are being presented to students.

Accordingly, in comparison with the species mentioned in the current curriculum and those based on the findings of the previous 2007 revised curriculum, about $60 \%$ of the species appeared identical. For the remaining $40 \%$ of species, it was found that the proportion of exotic plants such as Mangifera indica, Citrus $\times$ aurantium var. racemosa and Citrus $\times$ aurantium var. sinensis in the current textbooks was more than twice that of native plants. This is considered to have been caused by an attempt to reflect the change in plant species to textbooks in a social situation in which import, cultivation and sales of exotic plants have recently increased (Park, 2018; Jeong et al., 2020).

\section{Plant species and frequency by grade}

The number of plant species in textbooks by grade was similar in the $1^{\text {st }}$ and $2^{\text {nd }}$ grades (70 and 68 species, respectively), but showed a tendency to sharply increase by about 30 to 40 species in the $3^{\text {rd }}$ and $4^{\text {th }}$ grades. The number decreased by about 30 species to be 78 species in the $5^{\text {th }}$ grade, and was 97 species in $6^{\text {th }}$ grade with a slight increasing trend, indicating that the number of plants by grade was mainly focused in the $3^{\text {rd }}$ and $4^{\text {th }}$ grades, which are the stages proceeding to the upper grades. The frequency of appearance of plants by grade was the highest with 222 times in the 
Table 2. Frequency of plant species found in elementary school textbooks in Korea

$\langle N=1,047\rangle$

\begin{tabular}{cccc}
\hline Frequency & Scientific name of plants & Total No. \\
\hline 50 more & Malus pumila(75) & 1 \\
\hline Between & Glycine max (43) & 1 \\
$30-49$ & Musa $\times$ paradisiaca(29), Castanea crenata(22), Solanum lycopersicum(22), Citrullus vulgaris(21), Citrus unshiu(21), & 6 \\
Between & &
\end{tabular}

Daucus carota(19), Diospyros kaki(19), Ipomoea batatas(19), Zea may(19), Oryza sativa(18), Capsicum annuum(16), Pyrus pyrifolia var. culta(16), Brassica rapa subsp. pekinensis(15), Cucumis sativus(15), Pinus densiflora(15), Hibiscus

Between syriacus(14), Prunus persica(14), Solanum tuberosum(14), Vitis vinifera(14), Cucumis melo var. makuwa(13), Quercus

10-19 acutissim(13), Acer palmatum(12), Phaseolus vulgaris(12), Phyllostachys bambusoides(12), Rosa spp.(12), Allium fistulosum(11), Chrysanthemum morifolium(11), Taraxacum platycarpum(11), Solanum lycopersicum var. cerasiforme(10), Vigna angularis(10)

Arachis hypogaea, Lactuca sativa, Raphanus sativus, Rhododendron mucronulatum(8); Prunus salicina, Ginkgo biloba,

Between Ipomoea nil, Juglans regia, Nelumbo nucifera, Solanum melongena, Trifolium repens, Ziziphus jujuba var. inermis(7);

5-9 Allium cepa, Brassica oleracea var. capitata, Cucurbita moschata, Nymphaea tetragona, Prunus serrulata f. spontanea, Spinacia oleracea(6); Ananas comosus, Camellia sinensis, Citrus $\times$ aurantium var. sinensis, Forsythia koreana, Helianthus annuus, Hordeum vulgare, Sesamum indicum, Setaria viridis, Tulipa spp., Zelkova serrata(5)

Artemisia princeps, Citrus limon, Coffea arabica, Cosmos bipinnatus, Hydrilla verticillata, Impatiens balsamina, Magnolia

Between kobus, Pteridium aquilinum var. latiusculum, Spirodela polyrhiza(4); Allium sativum, Bidens bipinnata, Camelliajaponica,

3-4 Eichhornia crassipes, Juniperus chinensis, Lilium longiflorum, Paeonia suffruticosa, Pisum sativum, Prunus mume, Quercus myrsinaefolia, Salix koreensis, Typha orientalis(3)

Abies holophylla, Adansonia digitata, Aster yomena, Brassica napus, Brassica oleracea var. capitata f. rubra, Brassica oleracea var. viridis, Broussonetia $\times$ kazinoki, Capsicum annuum var. angulosum, Celosia argentea var. cristata, Chamaecyparis obtusa, Commelina communis, Cucumis melo, Cucurbita maxima, Erigeron anmuus, Fagopyrum esculentum, Gardenia jasminoides, Gossypium hirsutum, Gypsophila elegans, Imperata cylindrica var. koenigi, Juglans mandshurica, Mangifera indica, Oenanthe javanica, Paulownia coreana, Phragmites communis, Pinus koraiensis, Platycodon grandiflorus, Prumus armeniaca, Prunus dulcis, Prumus tomentosa, Pueraria lobata, Rhododendron obtusum, Rhododendron schlippenbachii, Rosa multiflora, Rubus crataegifolius, Saccharum officinarum, Sorghum bicolor, Theobroma cacao, Trapa japonica, Triticum aestivum, Ulmus davidiana var. japonica, Wisteria floribunda, Xanthium strumarium, Zoysia japonica(2); Acer saccharum, Acorus calamus, Agave americana, Allium monanthum, Allium $\times$ wakegii, Alnus japonica, Amaranthus mangostanus, Araucaria angustifolia, Arctium lappa, Ardisia pusilla 'Variegata', Aster spathulifolius, Bartramia spp., Beta vulgaris ssp. vulgaris, Betula pendula subsp. mandshurica, Betula schmidtii, Brassica oleracea var. gemmifera, Brassica oleracea var. gongylodes, Brassica oleracea var. italica, Calendula officinalis, Calystegia sepium var. japonicum, Capsella bursa-pastoris, Carpinus cordata, Carthamus tinctorius, Cereus peruvianus, Chenopodium album var. centrorubrum,

Under 2 Citrus $\times$ aurantiifolia, Citrus $\times$ aurantium var. racemosa, Citrus unshiu $\times$ C. sinensis $\times$ C. reticulata, Colocasia esculenta, Conyza canadensis, Cornus officinalis, Crescentia cujete, Cryptomeria japonica, Deschampsia antarctica, Dianthus caryophyllus, Dianthus chinensis, Dioscorea polystachya, Draba nemorosa, Drosera rotundifolia, Echinocactus grusonii, Elaeis guineensis, Eranthis stellata, Euonymus alatus, Euonymus japonicus, Euryale ferox, Fraxinus rhynchophylla, Hemerocallis fulva, Hemiptelea davidii, Hibiscus manihot, Hydrangea macrophylla, Lagenaria leucantha, Lespedeza bicolor, Lilium lancifolium, Luffa cylindrica, Manihot esculenta, Mirabilis jalapa, Morus alba, Morus australis, Mukdenia rossii, Musa $\times$ paradisiaca, Myriophyllum verticillatum, Nepenthes spp., Olea europaea, Ostericum grosseserratum, Oxalis corniculata, Panax ginseng, Papaver somniferum, Parthenocissus tricuspidata, Persicaria hydropiper, Pimpinella brachycarpa, Pinus thunbergii, Pistia stratiotes, Plantago asiatica, Platanus occidentalis, Populus davidiana, Populus maximowiczii, Portulaca grandiflora, Portulaca oleracea, Prunus avium, Pseudocydonia sinensis, Punica granatum, Quercus dentata, Rhus verniciflua, Rubia cordifolia var. pratensis, Rubus coreanus, Rubus idaeus var. concolor, Sagina spp., Salix babylonica, Salvia splendens, Salvinia natans, Sasa palmata, Saxifraga oppositifolia, Schisandra chinensis, Sedum takesimense, Setaria italica, Silene acaulis, Silene uralensis ssp. arctica, Sinapis arvensis, Stephanandra incisa, Syringa vulgaris, Tetragonia tetragonoides, Thlaspi arvense, Vallisneria natans, Viola mandshurica, Viola $\times$ wittrockiana, Vitis coignetiae, Zanthoxylum schinifolium(1)

Total

$*(\quad)$ : Frequency 
third grade, followed by 206 times in the first grade, 185 times in the fourth grade, and 173 times in the sixth grade, showing an irregular difference in frequency between grades (Fig. 1).

Meanwhile, as a result of re-analyzing the plants in the textbooks by grade group (MOE, 2015) organized by the Ministry of Education considering the connection of education between grades, 95 species (347 times) appeared in the $1^{\text {st }}$ and $2^{\text {nd }}$ grades, the lower grade group, and 166 species (407 times) in the $3^{\text {rd }}$ and $4^{\text {th }}$ grades, which continued to increase; while in the $5^{\text {th }}$ and $6^{\text {th }}$ grades, the upper grade group, 130 species (293 times) appeared, showing a clear tendency to decrease. It was found that this phenomenon also appeared in the 2007 revised curriculum textbook (Chun, 2014), and has continued to the present. It was expected that learning about plants would increase toward the upper grades, where cognitive ability increased, but the decrease in such learning starting from the $4^{\text {th }}$ grade was presumed to be due to the lack of rules on plants in the curriculum between grades. It is considered that the frequency of appearance of plants in the upper grades should be taken into account when developing textbooks so that this phenomenon can be improved in the next curriculum. In addition, it would be effective for the education to reduce the difference in the frequency of appearance of plants in textbooks between grades and to allow students to repeatedly encounter plants at a certain level. Furthermore, the $1^{\text {st }}$ and $2^{\text {nd }}$ grade groups, which are not exposed to diverse plant species due to the characteristics of the grade group, nevertheless showed 3.6 times higher frequency of plants than other grade groups. This is considered to be because the same plant name was repeatedly used as a material for the language do- main in the current education system that emphasizes Hangeul (Korean alphabet) learning for first and second graders who are just starting formal education (MOE, 2015).

\section{Plant species and frequency by subject}

Based on the analysis of plant species presented in each subject, Korean Language among all subjects showed a significantly higher frequency (295 times) and a greater number of plant species (142 species) than other subjects. Korean Language was followed by Science (154 times, 97 species) and Korean Language Activities (126 times, 70 species), so plants were mainly presented in the Korean Language. There was also a subject (Safe Life) that did not include plants at all. Accordingly, it was found that there was a large difference in the frequency of appearance of plants among 12 subjects (Fig. 2).

According to the analysis of plants between subject groups that were reclassified considering the relevance for educational purposes, the number and frequency of plant species was significantly higher in the Korean Language subject group. This is considered to be because the Korean Language subject group has a higher proportion of learning contents per unit than other subject groups, and the learning time allocated to the subject group is the longest, resulting in a high frequency of use of plants (MOE, 2015). The science subject group had the second highest number of plant species, but the frequency of appearance (186 times) was lower than that of the mathematics subject group (244 times). This is thought to be because, for science textbooks, plants were mainly presented only in the relevant unit, in which repetition
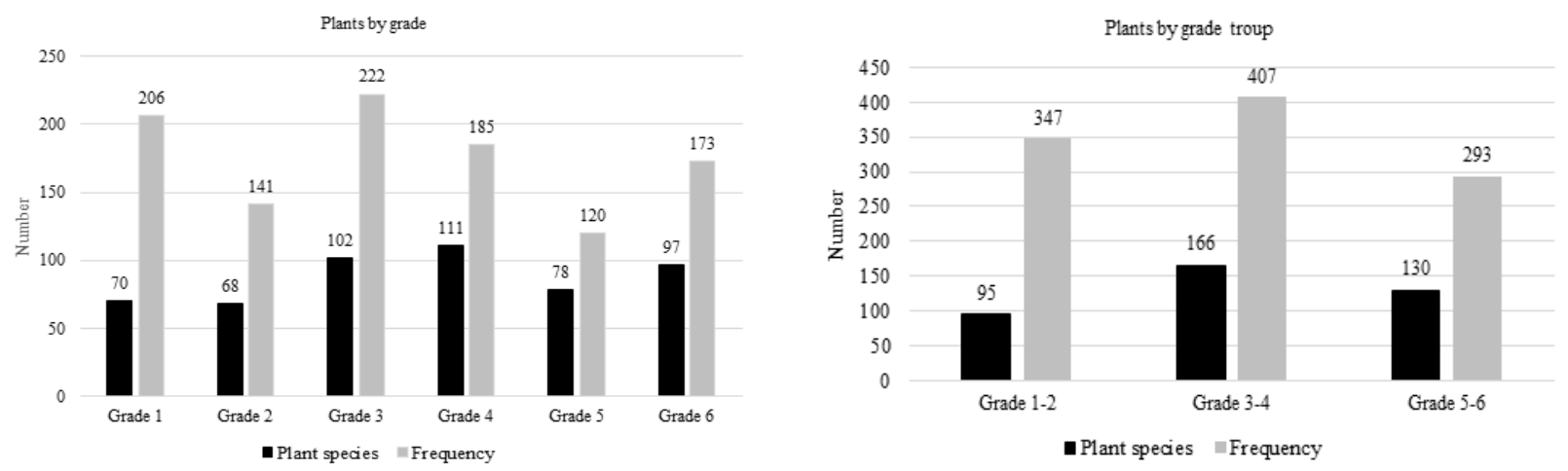

Fig. 1. Plant species and frequency by grade level in elementary school textbooks in Korea. 
of the same plant was concentrated (Bae, 2009).

In addition, the integrated curriculum group of Moral Life, Inquiring Life, and Pleasant Life, which occupied the lowest proportion among subjects, should have been able to deal with various plants according to the change of seasons due to the nature of the subjects. However, it is considered that the subject group cannot be expected to cover various plants as it contained indistinguishable data due to unclear illustrations or pictures in the subjects, and the number of units was relatively small compared to other subjects.

\section{Analysis of types in which plants were presented}

For types in which plants were presented by grade, texts (862 times) were the most common type, followed by illustrations (410 times) and photos (199 times). Of the types, text type was presented the most in the third grade (208 times), and illustration type was presented the most in the first grade (118 times), followed by the second grade (74 times). In addition, photo type was presented 54 times in the $1^{\text {st }}$ grade and 46 times in the $6^{\text {th }}$ grade, accounting for the majority, and 12 times in the $5^{\text {th }}$ grade showing the least number of times (Fig. 3). The reason why the proportion of illustration and photo types was high in the first grade is considered to be that these types can induce the concentration and interest of students, who are still in the early stages of language learning, through methods such as visual materials that are excellent at conveying realistic information, unlike texts (Lee, 2012; Park 2004). The reason why photo type appeared relatively frequently in $6^{\text {th }}$ grade is regarded to be because it is a method to help students understand the in-depth content of science subjects. Furthermore, as for plant parts, most of the illustrations and photos depicted fruits (including seeds), followed by whole plants and flowers.

Meanwhile in relation to the presentation in photo type, in Spring subject (page 61 in the textbook for the first semester of the first year), the photo of "Taraxacum coreanum" is incorrectly described as "Taraxacum platycarpum". and in Social Studies (page 40 in the textbook for the second semester of

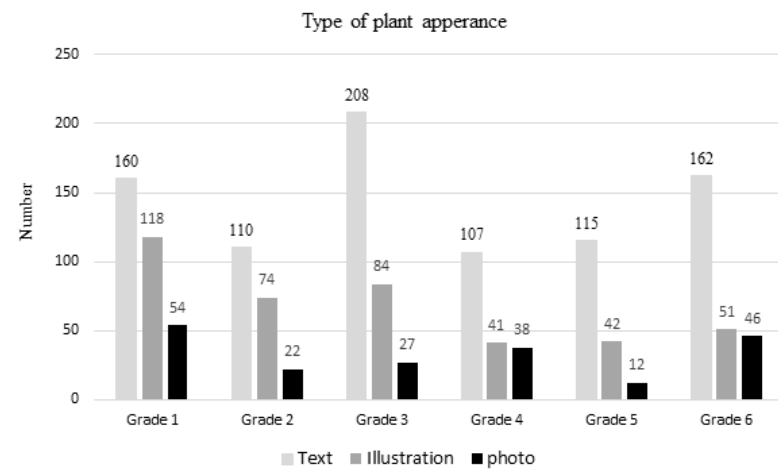

Fig. 3. Frequency of plant appearance by grade level in elementary school textbooks in Korea.

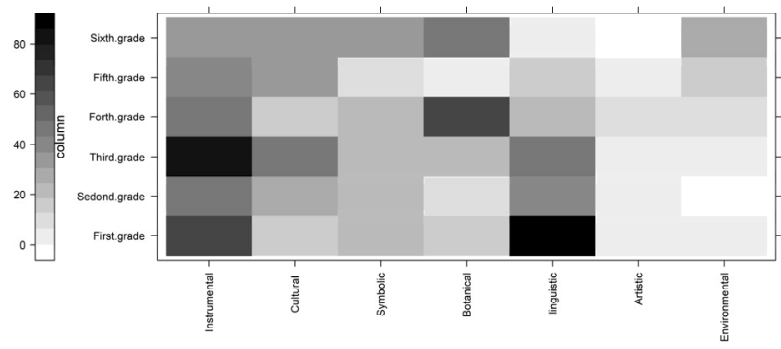

Fig. 4. The frequency distribution of plant learning content area by grade level in school textbooks in Korea.
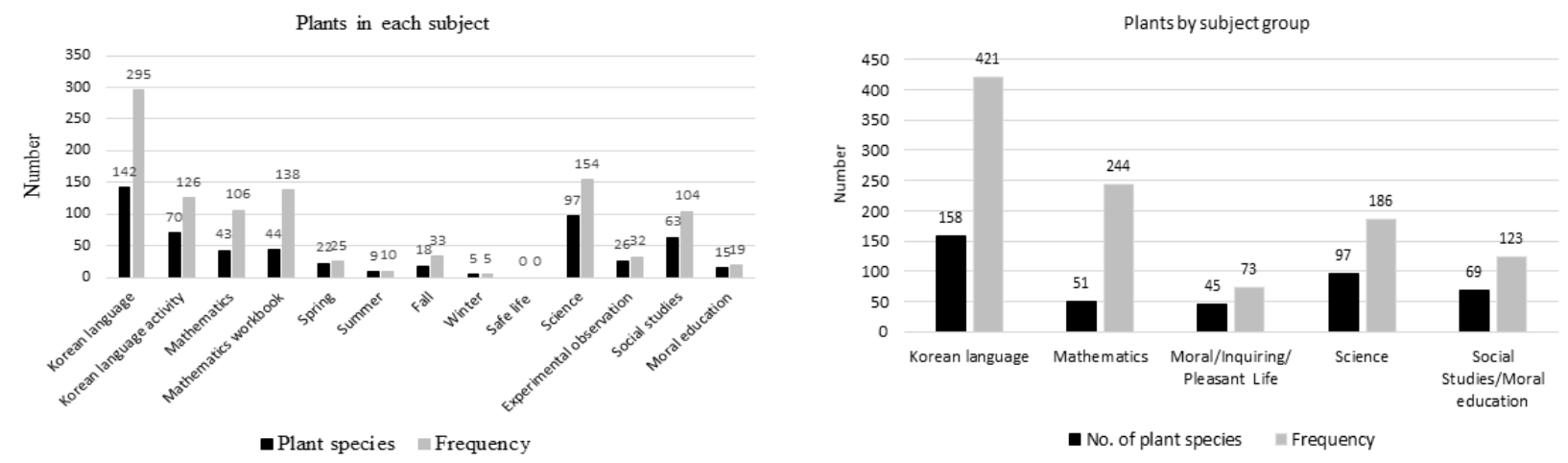

Fig. 2. Plant species and frequency by subject in school textbooks in Korea. 
the sixth grade), the photo described as "yam (Dioscorea polystachya)" is found to be actually that of "rutabaga (Brassica napus subsp. rapifera)" (Park, 2018; USDA GRIN, 2021). These photo-related erroneous presentation should be corrected in the next curriculum revision.

\section{Differences between grades by area of plant learning content}

Based on the analysis of the area of learning contents in which plants in the textbooks were used, in the first grade, the use of plants was highest in the linguistic domain, and in the third grade, the utilization of plants was high in the instrumental and cultural domains. In the $4^{\text {th }}$ grade, the use of plants in the botanical and artistic domains was significantly highest, and in the $6^{\text {th }}$ grade, such use was found to have the highest frequency in the environmental domain, followed by the domain of symbolic learning contents (Fig. 4). This difference in area of plant learning content by grade was found statistically significant as a result of the $X^{2}$ test: $X^{2}=343.911, p<.01$ (Table 3). These results seem to be in line with the current education direction, where the linguistic domain is mainly concentrated on in the first grade, the lower grade of elementary school. It was found that it was a desirable trend considering the characteristics of learning by grade that leaning in the botanical and environmental domains of natural sciences was treated as important in the 4th and 6th grades, the upper grades of elementary school. It can be seen that this reflects appropriate learning for each grade, because, even in public children's gardens in the United States, which provide curriculum-related educational programs, the lower grades focus on storytelling programs for language education, and the higher the grades focus more on ecological and environmental education (Kwon, 2016).

\section{Classification of plants based on the characteristics}

Of 232 plant species included in national textbooks, herbaceous plants accounted for 139 species (59.5\%), and woody plants accounted for 93 species (40.1\%), indicating that herbaceous plants were presented more frequently. For herbaceous plants, out of a total of 138 species, annual and biennial plants accounted for 74 (53.2\%), and perennial ones, 65 species (46.8\%), indicating almost a similar proportion (Table 4). This trend was found consistent with the findings of Kim (2004), who reported the analysis of the characteristics of plants presented in the 7th curriculum. Of the perennial, 46 species of perennial plants were presented in textbooks, 9 species

Table 3. Cross-analysis of plant learning content areas by grade level in school textbooks

\begin{tabular}{|c|c|c|c|c|c|c|c|c|}
\hline \multirow{2}{*}{\multicolumn{2}{|c|}{ Plant learning area }} & \multicolumn{6}{|c|}{ Grade } & \multirow{2}{*}{$X^{2} / \mathrm{p}$} \\
\hline & & \multirow{2}{*}{$\begin{array}{c}\text { Grade } 1 \\
65\end{array}$} & \multirow{2}{*}{$\begin{array}{c}\text { Grade } 2 \\
44\end{array}$} & \multirow{2}{*}{$\begin{array}{c}\text { Grade } 3 \\
82\end{array}$} & \multirow{2}{*}{$\begin{array}{c}\text { Grade } 4 \\
47\end{array}$} & \multirow{2}{*}{$\begin{array}{c}\text { Grade } 5 \\
42\end{array}$} & \multirow{2}{*}{$\begin{array}{c}\text { Grade } 6 \\
31\end{array}$} & \\
\hline To & Frequency & & & & & & & \\
\hline Instrumental & $\%$ & $20.9 \%$ & $14.1 \%$ & $26.4 \%$ & $15.1 \%$ & $13.5 \%$ & $10.0 \%$ & \\
\hline \multirow{2}{*}{ Cultural } & Frequency & 13 & 27 & 43 & 16 & 32 & 32 & \\
\hline & $\%$ & $8.0 \%$ & $16.6 \%$ & $26.4 \%$ & $9.8 \%$ & $19.6 \%$ & $19.6 \%$ & \\
\hline \multirow{2}{*}{ Symbolic } & Frequency & 24 & 24 & 22 & 21 & 12 & 36 & \\
\hline & $\%$ & $17.3 \%$ & $17.3 \%$ & $15.8 \%$ & $15.1 \%$ & $8.6 \%$ & $25.9 \%$ & \\
\hline \multirow{2}{*}{ Botanical } & Frequency & 15 & 8 & 21 & 62 & 2 & 43 & $X^{2}=343.911$ \\
\hline & $\%$ & $9.9 \%$ & $5.3 \%$ & $13.9 \%$ & $41.1 \%$ & $1.3 \%$ & $28.5 \%$ & $\mathrm{p}=.000$ \\
\hline \multirow{2}{*}{ Linguistic } & Frequency & 86 & 37 & 49 & 20 & 13 & 1 & \\
\hline & $\%$ & $41.7 \%$ & $18.0 \%$ & $23.8 \%$ & $9.7 \%$ & $6.3 \%$ & $0.5 \%$ & \\
\hline \multirow{2}{*}{ Artistic } & Frequency & 2 & 1 & 2 & 9 & 5 & 0 & \\
\hline & $\%$ & $10.5 \%$ & $5.3 \%$ & $10.5 \%$ & $47.4 \%$ & $26.3 \%$ & $0.0 \%$ & \\
\hline \multirow{2}{*}{ Environmental } & Frequency & 1 & 0 & 3 & 10 & 14 & 30 & \\
\hline & $\%$ & $1.7 \%$ & $0.0 \%$ & $5.2 \%$ & $17.2 \%$ & $24.1 \%$ & $51.7 \%$ & \\
\hline \multirow{2}{*}{ Total } & Frequency & 206 & 141 & 222 & 185 & 120 & 173 & 1047 \\
\hline & $\%$ & $19.7 \%$ & $13.5 \%$ & $21.2 \%$ & $17.7 \%$ & $11.5 \%$ & $16.5 \%$ & $100.0 \%$ \\
\hline
\end{tabular}


Table 4. Frequency of occurrence in school textbooks categorized by plant type

\begin{tabular}{|c|c|c|c|c|}
\hline & Division & Type & No. $(\%)$ & Total percentage \\
\hline \multirow{8}{*}{ Herbaceous plants } & \multicolumn{2}{|c|}{ Annuals and biennials } & $74(53.2 \%)$ & $31.9 \%$ \\
\hline & \multirow{6}{*}{$\begin{array}{c}\text { Perennial } \\
\text { flowers }\end{array}$} & Perennials & $46(33.1 \%)$ & $19.8 \%$ \\
\hline & & Foliage plants & $1(0.7 \%)$ & $1.7 \%$ \\
\hline & & Bulb and tubers & $4(2.9 \%)$ & $0.4 \%$ \\
\hline & & Cacti and succulents & $3(2.2 \%)$ & $1.3 \%$ \\
\hline & & Aquatic plants & $9(6.5 \%)$ & $3.9 \%$ \\
\hline & & Carnivorous plants & $2(1.4 \%)$ & $0.9 \%$ \\
\hline & & total & $139(100.0 \%)$ & $59.5 \%$ \\
\hline \multirow{7}{*}{ Woody plants } & \multirow{2}{*}{ Tree } & Evergreen & $21(22.6 \%)$ & $9.1 \%$ \\
\hline & & Deciduous & $41(44.1 \%)$ & $17.7 \%$ \\
\hline & \multirow{2}{*}{ Shrub } & Evergreen & $3(3.2 \%)$ & $1.3 \%$ \\
\hline & & Deciduous & $22(23.7 \%)$ & $9.5 \%$ \\
\hline & \multirow{2}{*}{ Vine } & Evergreen & $0(0.0 \%)$ & $0.0 \%$ \\
\hline & & Deciduous & $6(6.5 \%)$ & $2.6 \%$ \\
\hline & \multicolumn{2}{|c|}{ Subtotal } & $93(100.0 \%)$ & $40.1 \%$ \\
\hline \multicolumn{3}{|c|}{ Total } & 232 & $100 \%$ \\
\hline
\end{tabular}

of aquatic plants, 4 species of bulbs and tubers, 3 species of cacti and succulents, 2 species of carnivorous plants, and 1 species of foliage plant (Table 4). The number of foliage plants among them, which consisted of 4 species in the findings of Kim (2004) on the 7th curriculum, was found to have decreased in the current textbook. For woody plants, of a total of 93 species, (tall) trees accounted for 62 species, shrubs, 25 species, and vines, 6 species. Among them, 24 species of evergreens were presented in the textbooks, including 8 species of coniferous tree, 13 species of broadleaved trees and 3 species of evergreen shrubs, whereas 69 species $(74.3 \%)$ of deciduous trees were presented, which was much higher. Meanwhile, although the proportion among plants in the textbook was small, of 13 species of evergreen broad-leaved trees, except for Camellia japonica and Quercus myrsinaefolia (symbolic expressions), plants introduced from abroad such as Citrus $\times$ aurantium var. sinensis or mainly cultivated abroad such as Theobroma cacao were also presented. Accordingly, plants with various characteristics showed a tendency to be presented in the textbooks in a balanced way.

\section{Classification of crops}

As a result of analyzing the plants in the textbooks based on crop classification, of the crops excluding other crops, the frequency of appearance of horticultural crops was the highest, accounting for $69.4 \%$ of the total with 727 times (134 species), followed by food crops with 150 times (16 species). In addition, industrial crops were presented 29 times (11 species), stimulant crops, 11 times (3 species) and medicinal crops, 9 times (5 species), showing a significant difference in frequency between crops (Table 5). When comparing this with Kim (2004)'s findings with regard to the 7th curriculum, in which horticultural plants were presented the most, followed by industrial and edible plants, it was found that, in the current education, food-oriented life-related materials are mainly used based on the higher proportion of food crops after horticultural crops. For other crops, forest trees, wild flowers and weeds were presented the second most after food crops among all the crops, with 121 times (65 species). Out of horticultural crops, the number of flowering plant species (63 species) was the highest, but the frequency of appearance was the lowest with 204 times; while the frequency of fruit trees was the highest with 269 times, but the number of the species was the lowest. As shown by the above results, the high proportion of horticultural crops is considered to be because various horticultural crops are seen and used in everyday spaces such as homes and schools (Moon et al, 2010). 
Based on an analysis of the sub-categories of horticultural crops, which showed the largest proportion among crops, for fruit trees with the highest frequency of occurrence, temperate fruit trees (64.5\%) accounted for the majority compared to tropical and subtropical ones (35.5\%) (Table 6). This seems to be because many temperate deciduous fruit trees including apples and pears are cultivated in Korea, which is a temperate zone (Lim, 2016). Of the most frequently presented fruit tree species in the textbooks, the species of fruit trees that appeared more than 10 times, showed the same trend in both the 7th and 2007 revision curriculums (Chun, 2014; Kim, 2004). Next, for vegetables, leaf vegetables including napa cabbage and lettuce $(40 \%)$ were presented the most, followed by fruit vegetables such as strawberry $(32.5 \%)$, and root vegetables $(12.5 \%)$. This is regarded to be because Koreans eat a lot of kimchi and ssam (veggie wraps) (Lee, 2014). Lastly, of 63 species of flowering plants, woody plants (54\%) were presented slightly more than herbaceous plants (46\%); for herbaceous plants, the proportion of perennial plants $(28.6 \%)$ was higher than that of annual and biennial plants (17.5\%). This is considered to be because Koreans prefer flowering woody plants including Hibiscus syriacus, Rhododendron schlippenbachii, and Magnolia kobus, and they can be easily seen in daily life by planting a lot of easy-tomanage perennial flowers in the garden (Lee, 2008). For perennial flowers, 5 species of perennials and water plants, 3 species of cacti and succulents, 2 species of bulb and tubers, and 1 species of foliage plant were presented in the textbooks.

In this regard, "rose of sharon (Hibiscus syriacus), strawberries, apple trees, watermelons, grapes, persimmons, and sweet potatoes" reported in Chun (2014)'s findings on elementary school students' preferred plant by grade are all

Table 5. Classification of plants in elementary school textbooks by crop type

\begin{tabular}{|c|c|c|c|c|c|c|c|c|c|c|c|c|c|c|}
\hline \multicolumn{3}{|c|}{ Food crops } & \multicolumn{4}{|c|}{ Industrial crops } & \multirow{3}{*}{$\begin{array}{c}\text { Medicinal } \\
\text { crops }\end{array}$} & \multirow{3}{*}{$\begin{array}{l}\text { Stimulant } \\
\text { crops }\end{array}$} & \multicolumn{3}{|c|}{ Horticultural crops } & \multicolumn{3}{|c|}{ Etc. } \\
\hline \multicolumn{2}{|c|}{ Grain crops } & \multirow{2}{*}{$\begin{array}{l}\text { Root } \\
\text { and } \\
\text { tuber } \\
\text { crops }\end{array}$} & \multirow[b]{2}{*}{$\begin{array}{c}\text { Oil } \\
\text { crops }\end{array}$} & \multirow[b]{2}{*}{$\begin{array}{l}\text { Fiber } \\
\text { crops }\end{array}$} & \multirow[b]{2}{*}{$\begin{array}{l}\text { Sugar } \\
\text { crops }\end{array}$} & \multirow[b]{2}{*}{$\begin{array}{l}\text { Dye } \\
\text { crops }\end{array}$} & & & \multirow[b]{2}{*}{$\begin{array}{l}\text { Veget- } \\
\text { ables }\end{array}$} & \multirow[b]{2}{*}{$\begin{array}{l}\text { Fruit } \\
\text { trees }\end{array}$} & \multirow[b]{2}{*}{$\begin{array}{c}\text { Flowe- } \\
\text { ring } \\
\text { plants }\end{array}$} & \multirow[b]{2}{*}{$\begin{array}{l}\text { Forest } \\
\text { treess }\end{array}$} & \multirow[b]{2}{*}{$\begin{array}{l}\text { Wild } \\
\text { flowers }\end{array}$} & \multirow[b]{2}{*}{ Weeds } \\
\hline $\begin{array}{l}\text { Cereal } \\
\text { crops }\end{array}$ & $\begin{array}{l}\text { Pulse } \\
\text { crops }\end{array}$ & & & & & & & & & & & & & \\
\hline 49 & 66 & 35 & 8 & 17 & 2 & 2 & 9 & 11 & 254 & 269 & 204 & 43 & 31 & 47 \\
\hline (7) & (5) & (4) & (3) & (5) & (1) & (2) & (5) & (3) & (40) & $(31)$ & (63) & (22) & (24) & (19) \\
\hline
\end{tabular}

* Because of the overlapping uses of crops in the classification, the actual total number of plants does not match the total sum in Table 5.

Table 6. Classification and occurrence of horticultural crops in elementary school textbooks

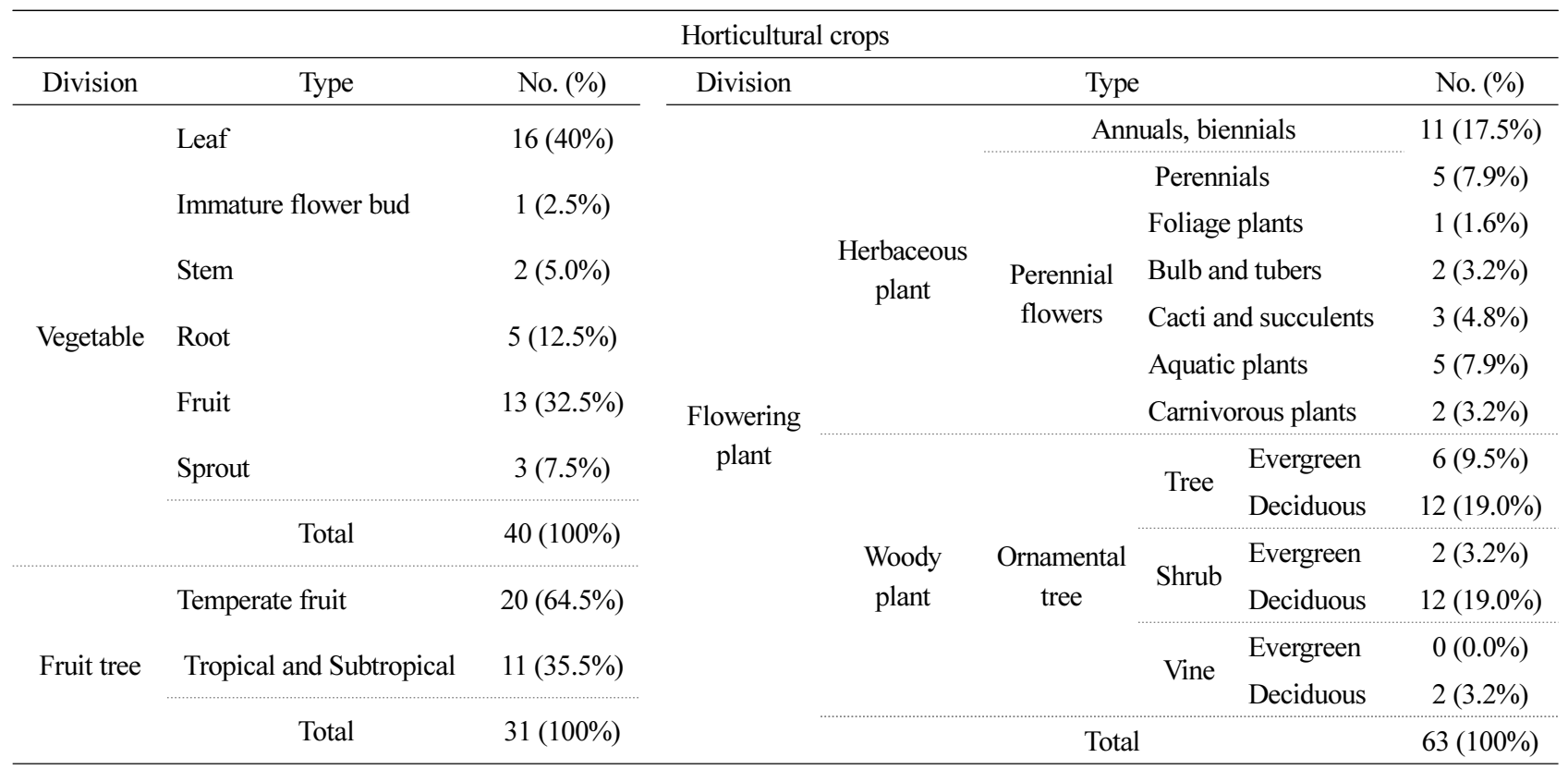


horticultural plants, which are found from a minimum of 14 times or more to a maximum of 70 times or more in current textbooks. Besides, due to climate change caused by global warming in recent years, tropical and subtropical fruit trees such as mango and banana, and subtropical vegetables such as asparagus and okras are grown in Jeju, Korea, and various tropical fruit trees are imported to and distributed in Korea (Jeong et al., 2020). Contrary to this trend, fruit trees are considered to be widely covered in the textbooks due to the dietary culture of eating fruits as dessert (Lee, 2014), but the number of such plant species that appeared is limited compared to the frequency of appearance (Table 5). However, in the future curriculum, it is expected that the presentation of new plants in textbooks - considering the current situation, such as the diversity of domestically grown plants due to environmental changes, and the use of imported tropical fruits - will become a realistic educational content that enhances the sense of the era of globalization.

In addition, according to the findings of Hwang (2010) and Lee (2012), the preferred plants of students who were exposed to horticultural activities outside the classroom were indoor plants, herbs and flowering plants; but based on the above-mentioned findings of Chun (2014) on main preference for plants in textbooks, it could be seen that the students were given more opportunities to experience plants, and the more they encountered various plants, the higher their interest in plants would be.

Based on the above results, it is considered that the textbooks on the next curriculum should be improved at the level of public education as follows: to cope with environmental changes such as global warming and social changes such as consumer demands, species of cultivated and horticultural plants in textbooks should be diversified (Park, 2018; Jeong et al., 2020) and reflected in consideration of students'preferences.

\section{Conclusion}

The purpose of this study was to present the direction of the next curriculum by determining the current status through the analysis of plants in the elementary school textbooks. Based on the 2015 revised national textbooks for all grades of elementary school, the results of the analysis of species and frequency of plants and crops presented in the textbook are as follows.

In the textbooks of all grades, a total of 232 species of plants were presented 1,047 times. The plants with the highest frequency were food plants, and the number and frequency of plant species overall decreased compared to the previous curriculums, but the species of plants that appeared once were more diverse.

As in the previous curriculums, the number of plant species by grade continued to decrease toward higher grades. In the direction of the next curriculum, it is considered that the number of plant species should be increased in the upper grades in consideration of secondary education. The number of plant species was presented the most in Korean Language, but in preparation for the future development of natural science and the cultivation of a nature-friendly human character, measures to increase the proportion of plants in science textbooks should be considered.

As for the areas in which plants were used in the textbooks, for the first grade, the proportion of plants was the highest mainly in the linguistic domain; and for the $5^{\text {th }}$ and $6^{\text {th }}$ grades, the upper grades, plants were used a lot in the botanical, artistic, and environmental domains, which is regarded to be the result of considering level and stage of learning by grade.

The type of presentation of plants through text was the most, followed by illustrations and photos of plants. Illustrations and photos of plants were used a lot in the first grade, the first stage of learning. Many unclear parts were found in the illustrations of the textbooks investigated, and in particular, a few parts with a plant name different from the photo were discovered for the first time in this study. Such illustrations and photos need to be revised to increase clarity and match the plant names.

The plants in the textbooks were generally various herbaceous and woody plants, but as a result of the analysis of the crops classified to understand the degree of connection with real life, horticultural crops were presented the most, and of them, the frequency of fruit trees was highest. It means that most of the current textbooks consist of food-oriented plant species that are commonly seen in daily life, but the plants presented in a high proportion remain largely unchanged 
from the plant species presented in the previous curriculums.

Therefore, based on the findings of this study, it is considered important to propose a plan that embraces a wide range of plants in consideration of changes in the global environment and students' preferences rather than focusing on edible plants when developing textbooks in the next curriculum. Furthermore, various plants (indoor air purifying plants, herbs, medicinal plants, etc.) should be evenly reflected that are used more in real life, including Western vegetables and tropical fruit trees according to social changes. Lastly, it is regarded very important to present a learning plan using plants that can be connected to science in life in accordance with the current circumstances.

\section{References}

Ahn, S.Y. 2012. Analysis of real life-related problems in 1st-grade textbooks of high school. Master's thesis, Korea University, Seoul, Korea.

Bae, H.W. 2009. Analysis of connection between characteristics and learning topics of plant species appearing in elementary and secondary school textbooks -focused on the subject of biological in the 7th science and curriculum-. Master's thesis, Korea University, Seoul, Korea.

Choi, W.J. 2007. Effects of real life material science-teaching activity on the scientific attitudes and the scientific inquiry skills of 6th-grade elementary school students. Master's thesis, Korea National University of Education, Chung-Buk, Korea.

Chun, M.P. 2014. Research on plants in elementary school textbook and plants in elementary schools. Doctoral dissertation, Daegu Haany University, Gyeongbuk, Korea.

Hwang, J.H. 2010. The analysis of plant group and the development of elementary horticulture education teaching guide based on the concept of green pet. Master's thesis, Seoul National University of Education, Seoul, Korea.

Jeong, U.S., S.S. Kim, and Y.W. Chae. 2020. Analysis on the cultivation trends and main producing areas of subtr opical crops in Korea. J. Korea Acad. Ind. Coop. Soc. 21(12):524-535. https://doi.org/10.5762/KAIS.2020.21. 12.524
KFS(Korea Forest Service). 2020. March. 6. Korean plant names index committee. Retrieved from http://www.nat ure.go.kr/kpni/index.do.

Kim, I.J. 2008. Citrus cultivars. Jejudo, Korea: Inst. of Subtropical Agriculture and Bio-science.

Kim, M.R. 2008. Strategies to utilize plants in urban parks for elementary, middle \& high school biology - Focused on urban parks located in Bundang-gu, Seongnam-si. Master's thesis, Chungnam National University, Chungnam, Korea.

Kim, S.K. 1998. Study on the classificaion and recognition of plants dealt in textbook of Korean elementary school. Master's thesis, Kyungsung University, Busan, Korea.

Kim, Y.C. 2004. A study on the species and classification of plants within the elementary school textbooks. Master's thesis, Chinju National University of Education, Chinju, Korea.

Kwon, M.H. 2016. Status and education programs of public children's gardens In the United States. Doctoral dissertation, Korea University, Seoul, Korea.

Lee, H.Y. 2012. Analysis of plant horticultural activity characteristics and preference of multicultural children. Master's thesis, Seoul National University of Education, Seoul, Korea.

Lee, J.M, 2014. Vegetable science general (pp. 1-40). Seoul, Korea: Hyangmunsa.

Lee, J.S. 2008. Floriculture (pp. 22-43). Seoul, Korea: Hyangmunsa.

Lee J.H. 2010. A study on the various images used in music textbooks for the elementary school -mainly focusing on the third grade and their music textbooks for Korea, the United States of America and Germany-. Master's thesis, Gwangju National University of Education, Gwangju, Korea.

Lee, S.H. and J.S. Cho. 2005. Development and application of ICT teaching - learning process plan for Environmentally friendly housing - For an academic girl's high school in Gwangju Metropolitan City. J Home Econ. Educ. Res. 17(4):101-115.

Lim, H.J. 2012. Factors affecting short-term memory recall of vocabulary for elementary school EFL learners: with reference to picture information and categorization information. Master's thesis, Soongsil University, Seoul, Korea. 
Lim, J.W. 2007. An analysis of higher plants-related learning contents in science textbooks of elementary and secondary schools regarding on educational curriculum change. Master's thesis, Kangwon National University, Kangwon, Korea.

Lim, Y.H. 2003. An analysis on biology materials presented on elementary science textbooks of the 7th curriculum Focused on the life field. Master's thesis, Jeonju National University, Jeonju, Korea.

Lim, Y.J. 2016. Fruit crops (pp. 52-53). Seoul, Korea: Hyangmunsa.

MOE (Ministry of Education). 2015. Introduction to the elementary and secondary school curriculum. Min. Educ. Notice No. 2015-74. Retrieved from https://www.moe.g o.kr/boardCnts/view.do?boardID=141\&boardSeq=6074 $7 \&$ lev $=0 \&$ searchType $=$ null $\&$ status $Y N=W \&$ page $=20 \& \mathrm{~s}$ $=$ moe $\& \mathrm{~m}=040401 \&$ op Type $=\mathrm{N}$

Moon, W., C.H. Chun, and J.W. Lee. 2010. Horticulture (pp. 44-50). Seoul, Korea: Korea National Open University Press.

Nam, S.I. 2006. The effects of plant observation activity on the attitudes of elementary school students' environmental conservation. Master's thesis, Dankook University, Seoul, Korea.

NCIC (National Curriculum Information Center). 2020. Jan. 3. Retrieved from http://ncic.go.kr/mobile.dwn.ogf.inve ntoryList.do

NIFS (National Institute of Forest Science). Korean tree encyclopedia search. 2021. Jan. 10. Retrieved from http:// know.nifos.go.kr/know/service/apiSearch/wdptpilbkm.do

NIHHS (National Institute of Horticultural and Herbal Science). 2020. Major tropical and subtropical fruit trees. Global Warm. Resp. Agri. Res. Center, NIHHS, RDA, Korea.

NIKL (National Institute of Korean Language). 2020. March. 6. Standard Korean language dictionary. Retrieved from https://stdict.korean.go.kr/main/main.do

Park, J.G. 2003. A study on semantic differential of plants in elementary textbooks and their education. Master's thesis, Busan University, Busan, Korea.

Park, H.J. and J.S. Cho. 2009. Development and application of issue-centered teaching.learning process plan for environment-friendly housing education. J Home Econ. Educ. Res. 21(3):45-64.
Park, J.J. 2004. Analyzing the species of plants, the contents of learning and the frequency of them that appear in the elementary school textbooks and groping for the betterment. MS Thesis, Yeungnam University, Daegu, Korea.

Park, K.W. 2018. Western vegetable (pp. 51-54). Seoul, Korea: Worldscience Co.

Park, S.J., J.C. Chae, B.H, Kang, and S.H. Kim. 2006. Cultivation principles (3rd ed.) (pp. 34-39). Seoul, Korea: Hyangmunsa.

Pyo, S.H. 2001. A study of elementary school students preference level on plants appeared in their textbooks. Master's thesis, Korea National University of Education, ChungBuk, Korea.

RDA (Rural Development Administration). 2013. Korean native flower cultivation. Agri. Tech. Guide. 138 (Revised). Retrieved from file://C:/Users/user/Desktop/1.\%20\%E B $\% 85 \%$ BC $\%$ EB $\%$ AC $\%$ B $8 \%$ EA $\%$ B2\%8C $\%$ EC $\% 9 \mathrm{E} \%$ AC_\%EC\%9D\%B8\%EC\%8B\%9D\%ED\%99\%98/\%E C\%B0\%B8\%EA\%B3\%A0\%EB\%AC\%B8\%ED\%97\%8 C/\%ЕC\%9A\%B0\%ЕB\%A6\%AC\%EA\%BD\%83\%E A\%B8\%B0\%EB\%A5\%B4\%EA\%B8\%B0_\%20\%ЕC\% $95 \% \mathrm{BC} \% \mathrm{EC} \% 83 \% 9 \mathrm{D} \% \mathrm{ED} \% 99 \% 94 \_\% \mathrm{~EB} \% 86 \% 8 \mathrm{D} \%$ EC\%82\%AC\%EB\%A1\%9C.PDF

RDA (Rural Development Administration), 2018. Weed control technology. Agric. Tech. Guide 41 (Revised). Retrieved from https:/www.nongsaro.go.kr/portal/ps/psb/psbx/cropEbo okFileViewPop.ps?indexPage $=11 \&$ indexBasePage $=-1 \&$ cropsEbookFileNo $=00001 \&$ ebookCode $=23$

RDA (Rural Development Adminustration). 2021. Jan. 15. Nongsaro, Agricultural technology portal, Korea. Retrieved from https://www.nongsaro.go.kr/portal/portalMain.ps? menuId=PS00001

Rubatzky, V.E. and M. Yamaguchi. 2012. World vegetables: Principles, production and nutritive values (pp. 29-33). Springer Science \& Business Media.

Seo, Y.J. 2009. An analysis on real world questions in middle school mathematics I under the 2007 revised national curriculum. Master's thesis, Keimyung University, Daegu, Korea.

USDA GRIN (U.S Department of Agriculture). 2021. Jan. 6. U.S. National plant germplasm system. Retrieved from https:/npgsweb.ars-grin.gov/gringlobal/taxon/taxonomy search 
Yun, H.S. and Y.D. Rim. 2000. Effects of providing plant names to elementary school low grade students and plant recognition. J. Korean Soc. Biol. Educ. 28(4):356-362.
Yun, H.S. 2000. Effects of providing plant names to elementary school low grade students and plant recognition. Master's thesis, Incheon National University of Education, Incheon, Seoul. 